\title{
Health Utility Scores of Hearing-Impaired Thais
}

\author{
Pittayapon Pitathawatchai, M.D., MClinAud1, Wirawan Wannaro, B.Sc. ${ }^{1}$, \\ Patchanok Pongprawat, B.Sc. ${ }^{1}$, Thara Tunthanathip, M.D. ${ }^{2}$, Luiz Lourencone, M.D., Ph.D. ${ }^{3}$
}

'Department of Otolaryngology Head and Neck Surgery, ${ }^{2}$ Division of Neurosurgery, Department of Surgery,

Faculty of Medicine, Prince of Songkla University, Hat Yai, Songkhla 90110, Thailand.

${ }^{3}$ Hospital for Rehabilitation of Craniofacial Anomalies, University of Sao Paulo, Bauru 17012-900, Brazil.

Received 2 August 2019 • Revised 30 October 2019 • Accepted 5 November 2019 • Published online 22 November 2019

\section{Abstract:}

Objective: To assess the health utility scores of Thais with hearing loss, which can be used as a reference value for assessing health-related quality of life and economic evaluations in any interventions among hearing-impaired persons in Thailand.

Material and Methods: All hearing-impaired persons who visited Songklanagarind Hospital between January and June 2019 were recruited for the study. The demographic and clinical data of the participants including gender, age, and type and degree of hearing loss were collected. A health-related quality of life interview was conducted using the EuroQoL five-dimensional questionnaire, Thai version. Independent t-test and multiple linear regression analysis were performed to assess which factors were associated independently with the health utility scores.

Results: One hundred and eleven participants, 46 males and 65 females, ranging in age from 22 to 92 years, were recruited for the study. The average health utility scores were 0.81 and 0.86 for subjects not using and using hearing aids, respectively, similar to the results from other nations. The average health utility score of subjects with underlying diseases (0.79) was lower than the average health utility score of subjects without underlying diseases (0.87) with statistical significance $(p-v a l u e=0.038)$. Additionally, the pure tone average in the better ear was the only variable significantly associated with the health utility scores (regression coefficient: -0.004 , p-value=0.002).

Conclusion: The average health utility scores among hearing-impaired Thais were 0.81 and 0.86 for subjects not using and using hearing aids, respectively.

Keywords: EQ-5D, hearing loss, Thai, utility scores

Contact: Department of Otolaryngology Head and Neck Surgery,

Faculty of Medicine, Prince of Songkla University, Hat Yai, Songkhla 90110,

Thailand.

E-mail: pittayapon.p@psu.ac.th

(c) 2020 JHSMR. Hosting by Prince of Songkla University. All rights reserved.

This is an open access article under the CC BY-NC-ND license

(http://www.jhsmr.org/index.php/jhsmr/about/editorialPolicies\#openAccessPolicy).
J Health Sci Med Res 2020;38(1):17-24 doi: 10.31584 /jhsmr.201973 www.jhsmr.org 


\section{Introduction}

Hearing loss is recognized as one of the most common disorders, and is associated with variable etiologies. This disability can also result in academic underachievement and decreased employment opportunities. ${ }^{1}$ It is estimated that around 466 million persons across the world suffer from hearing loss. ${ }^{2}$ In Thailand, approximately 11.6-13.6 percent of the population have hearing loss ${ }^{3,4}$ and overall Thai populations were estimated at over 66.4 million in the year of $2018 .^{5}$ As the number of hearing-impaired individuals in the general populations is high, any interventions provided for this disability will involve a considerable expenditure. Generally, the 2 main costly interventions, based on the number of uses nationwide and the price of devices for treating hearing-impaired persons, are hearing aid fitting and cochlear implantations, respectively. The Thai government provides all hearing-impaired individuals with a hearing aid under the Universal Health Coverage, while cochlear implantations are only provided under the Civil Servant Medical Benefits Scheme. In 2017, it was estimated that over 1.3 million civil servants were covered under this Civil Servant Medical Benefit Scheme. ${ }^{6}$ In regards to the hearing aid fitting, the Thai government provides all Thai adults who are confirmed to have permanent hearing impairment with a one-side hearing aid without cost to the patient, at a maximum price of 435 United States Dollars (US\$435). Both-sides hearing aids are provided for all Thai children confirmed to have permanent hearing impairment without cost to the patient, at a maximum price of US $\$ 480$ for each side. In terms of the cochlear implantation provided under the Civil Servant Medical Benefit Scheme without cost to the patient, a maximum price of US $\$ 27,000$ is set for a one side implant by the government.

Therefore, in terms of economic evaluations, it is necessary for the government to evaluate the cost effective- ness of the interventions associated with hearing-impaired persons in order to effectively allocate limited resources to meet all health needs across the whole country. To analyse the cost effectiveness in the interventions associated with hearing loss including hearing aid fitting and cochlear implantations, collecting data on health utility scores (HUSs) is an imperative initial step to measure health-related quality life among those hearing-impaired individuals. Specifically, the HUS is a value used to address the level of health status which is measured by individual preference ranging from 0 (death) to 1 (perfect health). ${ }^{7}$ The HUS can then be used to weight the number of life years in a specific disorder into the number of life years in perfect health, which is known as Quality-Adjusted Life Years (QALYs). For instance, 10 years of life lived with hearing loss with a utility of 0.8 is equivalent to 8 years of life lived in perfect health (10 years $\times 0.8$ utility). Various studies have reported that the HUS in individuals with bilateral hearing loss ranged from 0.77 to $0.89 .^{8-11}$

However, due to significant differences in culture and socioeconomic status among countries, the HUSs also vary among those countries. ${ }^{12}$ Therefore, it is important that the HUS for a specific disorder is obtained from an individual local area. $^{13}$ In Thailand, studies on the HUSs among hearing-impaired Thais are scarce; as a result, the cost effectiveness of any interventions for hearingimpaired Thais cannot be reliably assessed. Therefore, the present study aimed to report the health utility scores of Thais with hearing loss, which can then be used as a reference value for assessing health-related quality of life and economic evaluations in any interventions among hearing-impaired persons in Thailand.

\section{Material and Methods}

This research was an observational study (a survey). Data collection was approved by the Institutional Review 
Board, Faculty of Medicine, Prince of Songkla University. All subjects gave informed consent before they were enrolled in the study.

\section{Subjects}

All hearing-impaired persons over 18 years of age who visited Songklanagarind Hospital between January and June 2019 were recruited for the study. Participants who were scheduled for additional medical or surgical treatment due to possible hearing improvement from such treatments were excluded. Additionally, participants who had cognitive impairment, for instance dementia or mental retardation, were excluded.

\section{Hearing loss definitions}

Hearing loss was diagnosed when the hearing threshold in either ear at any frequency between 0.25-8 kilohertz $(\mathrm{kHz})$ was worse than 25 decibel hearing level $(\mathrm{dBHL})$ in audiometry assessment. ${ }^{14}$ All types of permanent hearing loss were included, namely conductive hearing loss, sensorineural hearing loss and mixed hearing loss. Pure tone averages (PTA) of $0.5,1$ and $2 \mathrm{kHz}$ were used to define the degree of hearing loss, which were mild (26-40 dBHL), moderate (41-55 dBHL), moderately severe (56-70 dBHL), severe (71-90 dBHL) and profound (>90 $\mathrm{dBHL})$.

\section{Procedure}

All participants were informed in regard to the study aim, process and results, and if they agreed to participate, they signed the consent form. Baseline demographic and clinical characteristics including gender, age, underlying disease(s), type and degree of hearing loss, and previous hearing-related treatments were collected. Then an interview to assess their health-related quality of life was conducted by the researchers using a questionnaire called the EuroQoL five-dimensional (EQ-5D-5L), Thai version with permission from the EuroQol Group. The questionnaire consists of 5 dimensions, namely mobility, self-care, usual activities, pain/discomfort and anxiety/depression. Each dimension has 5 levels which are no problems, slight problems, moderate problems, severe problems, and extreme problems. In terms of the HUS calculation, firstly, we assumed a baseline HUS of 1 (perfect health), and then reduced the score accordingly based on the ratings from the 5 levels in each dimension of the EQ-5D-5L as reported by the subjects. That is, the higher the level they rated for each individual item, the lower the final HUS score.

\section{Statistical analysis}

The clinical features of the participants are described using descriptive statistics. Age, PTA of the better ear and the HUS were continuous variables, which were analyzed using correlation analysis.

Independent t-test was used to show differences in the HUSs between subjects with or without underlying diseases as well as using and not already using hearing aids.

Simple and multiple linear regression analysis were performed to assess which factors were associated independently with the HUSs. Baseline characteristics and PTA of the better ear parameters were assigned as independent variables and the HUSs were assigned as a dependent variable. The Shapiro-Wilk test was performed for testing normality from dependent variables. In the simple regression analysis, a threshold of $\mathrm{P}$ less than 0.1 was used to recognize candidate factors for inclusion in the multiple linear regression. The multiple regression was performed using the forward selection procedure. $\mathrm{P}$-values less than 0.050 were regarded as statistically significant. The statistical analysis was performed using the $\mathrm{R}$ program, version 3.4.0 software (R Foundation, Vienna, Austria). 


\section{Results}

One hundred and eleven hearing-impaired persons, 46 males and 65 females, ranging in age from 22 to 92 years, were recruited for the study. Seventy two of the participants had one or more underlying diseases, including chronic rhinitis, benign prostate hypertrophy, cataract, dyslipidemia, diabetes and/or hypertension. Twenty-five were already using hearing aids. Table 1 shows the baseline characteristics of all subjects in the study. For testing of normality, all variables were not significantly different in the Shapiro-Wilk test, showing a normal distribution.

The range of the HUSs is shown in Table 2 according to the degree of hearing loss in the better ear and subjects using or not using hearing aids. Note that there were also a number of hearing-impaired persons showing high frequency hearing loss with normal PTA $(\leq 25 \mathrm{dBHL})$ included in the study.

Although the average HUS among all subjects not using hearing aids (0.81) was lower than the HUS among all subjects using hearing aids (0.86), the difference was not statistically significant $(p-v a l u e=0.200)$ in the in dependent t-test analysis (Table 3). In contrast, when only subjects not using hearing aids were included $(n=86)$ for the independent t-test analysis, the average HUS of subjects with one or more underlying diseases (0.79) was lower than the average HUS of subjects without underlying diseases (0.87), which was statistically significant ( $p$-value $=0.038$ ).

Table 1 Baseline characteristics $(n=111)$

\begin{tabular}{ll}
\hline Factor & Number (\%) \\
\hline $\begin{array}{l}\text { Mean age (years) } \\
\text { Age (years) }\end{array}$ & $65.9($ S.D. $=14.2)$ \\
$\quad \leq 65$ & $46(41.4)$ \\
$\quad>65$ & $65(58.6)$ \\
Type of right ear hearing loss & \\
SNHL & $82(73.9)$ \\
CHL & $6(5.4)$ \\
Mixed HL & $23(20.7)$ \\
Type of left ear hearing loss & \\
SNHL & $82(73.9)$ \\
CHL & $5(4.5)$ \\
Mixed HL & $24(21.6)$ \\
Mean PTA in the better ear & $48($ S.D.=16.8) \\
Number of subjects with underlying & $72(64.9)$ \\
disease(s) & \\
Number of subjects using hearing aid(s) & $25(22.5)$ \\
\hline
\end{tabular}

$\mathrm{SNHL}=$ sensorineural hearing loss, $\mathrm{CHL}=$ conductive hearing loss, mixed $\mathrm{HL}=$ mixed hearing loss, PTA=pure tone average, HUS=health utility score, S.D.=standard deviation

Table 2 The health utility scores according to the degree of hearing loss in the better ear

\begin{tabular}{|c|c|c|}
\hline \multirow{2}{*}{$\begin{array}{l}\text { Degree of hearing loss (dBHL) } \\
\text { in the better ear }\end{array}$} & $n=86$ & $n=25$ \\
\hline & $\begin{array}{l}\text { HUS in subjects not using } \\
\text { hearing aids (S.D., SE) }\end{array}$ & $\begin{array}{l}\text { HUS in subjects using hearing } \\
\text { aids (S.D., SE) }\end{array}$ \\
\hline High tone loss $(\leq 25)$ & $0.88(0.10,0.02)$ & None \\
\hline Mild (26-40) & $0.89(0.10,0.002)$ & None \\
\hline Moderate (41-55) & $0.80(0.18,0.03)$ & $0.85(0.1,0.04)$ \\
\hline Moderately severe $(56-70)$ & $0.72(0.19,0.05)$ & $0.83(0.12,0.04)$ \\
\hline Severe $(71-90)$ & $0.78(0.10,0.06)$ & $0.97(0.05,0.02)$ \\
\hline Profound (>90) & $0.35^{\star}$ & $0.78^{*}$ \\
\hline Average of all degrees & $0.81(0.17,0.02)$ & $0.86(0.12,0.02)$ \\
\hline
\end{tabular}

*Only one subject had hearing loss at this level, S.D.=standard deviation, SE=standard error, HUS=health utility score 
Table 3 Independent t-test results of health utility score comparisons in subjects with/without hearing aid fitting, with/without underlying diseases, age group and gender

\begin{tabular}{lll}
\hline Factor & Mean HUS (S.D.) & p-value \\
\hline $\begin{array}{l}\text { Hearing aid fitting } \\
\quad \text { No }\end{array}$ & $0.81(0.17)$ & 0.200 \\
$\quad$ Yes & $0.86(0.12)$ & \\
Underlying disease(s) & & 0.038 \\
$\quad$ No & $0.87(0.12)$ & \\
$\quad$ Yes & $0.79(0.18)$ & \\
Age group (years) & & 0.930 \\
$\quad<60$ & $0.80(0.14)$ & \\
$\quad \geq 60$ & $0.81(0.17)$ & 0.210 \\
Gender & $0.83(0.14)$ & \\
$\quad$ Male & $0.79(0.18)$ & \\
$\quad$ Female & & \\
\hline
\end{tabular}

HUS=health utility score, S.D.=standard deviation

To determine multicollinearity problems in the multiple regression analysis, variance inflation factors and tolerance analyses were performed. The results from the multiple linear regression analysis run by the forward selection procedure are presented in Table 4. The multiple linear regression analysis showed that PTA in the better ear was the only variable significantly associated with the HUSs (regression coefficient: $-0.004, p-v a l u e=0.002$ ).

\section{Discussion}

Our study found that the average HUSs among hearing-impaired Thais $(0.81$ to 0.86$)$ are similar to the scores in other countries (0.77 to 0.89). ${ }^{8-11}$ The EQ-5D-5L is not the only assessment tool which has been used to assess the HUSs for hearing impaired persons. In the United Kingdom, different questionnaires including the Health Utilities Index Mark III, the preference-based Short Form $6 D$ and the EQ-5D-5L have been used to estimate the HUSs of hearing impaired persons, with findings of $0.58,0.78$ and 0.80 , respectively. ${ }^{15}$ It should also be noted that Thailand is considered as a developing country, and therefore our results might be more relevant to other lowand middle-income countries than high-income nations.

In terms of dimensions, namely mobility, self-care, usual activities, pain/discomfort and anxiety/depression in the EQ-5D-5L, another study reported that mobility was considered as the most important health issue in the general Thai population. ${ }^{16}$ However, when each dimension in the EQ-5D-5L of our data was analyzed, we found that limitations in usual activities was the most important dimension, and which improving the HUSs for hearing impaired Thais would be most beneficial in our study setting. This is reasonable because when hearing impaired persons cannot hear or understand other people speak-

Table 4 Multiple linear regression of factors associated with EQ-5D-5L index values with the forward selection procedure

\begin{tabular}{|c|c|c|c|c|}
\hline Factor & Regression coefficient $(95 \% \mathrm{Cl})$ & $p$-value & Tolerance & VIF \\
\hline \multicolumn{5}{|l|}{ Initial model } \\
\hline Intercept & 0.984 & & & \\
\hline PTA in the better ear & $-0.003(-0.005,0.000)$ & 0.010 & 0.911 & 1.098 \\
\hline \multicolumn{5}{|l|}{ Final model } \\
\hline Intercept & 0.970 & & & \\
\hline PTA in the better ear & $-0.004(-0.006,-0.001)$ & 0.002 & - & - \\
\hline
\end{tabular}

$\mathrm{Cl}=$ confidence interval, PTA=pure tone average, $\mathrm{VIF}=$ variance inflation factors 
ing in their daily communications, certainly, they cannot participate well in such activities such as working and studying. It has been reported in the literature that the worse the hearing impairment, the more limited the usual activities of hearing-impaired individuals, and the difference was statistically significant. ${ }^{17,18}$

We also found that the degree of hearing loss had a negative correlation with the HUSs as shown in the multiple regression analysis (regression coefficient: -0.004, p-value=0.002). In other words, the higher the degree of hearing loss, the lower the HUS. This is also sensible and has also been noted in other studies in the literature. For instance, the HUS ranges of mild and severe degrees of hearing loss were 0.89-0.92 and 0.81-0.86, respectively. ${ }^{19-21}$ Regarding underlying diseases, including chronic rhinitis, benign prostate hypertrophy, cataract, dyslipidemia, diabetes and hypertension which were observed in 72 of our subjects, we found that the average HUS of these participants (0.79) was significantly lower than in those without underlying diseases (0.87) when analyzed by independent t-test $(p-v a l u e=0.038)$. Even though these underlying diseases are generally mild and not life-threatening conditions, we emphasize that it is important to acknowledge these conditions because they can have a significant effect on the HUS in hearing-impaired individuals.

We found that the average HUSs of subjects not using hearing aids (0.81) was lower than those using hearing aids (0.86); however, the difference was not statistically significant ( $p$-value $=0.200$ ). That is, the use of hearing aids did not result in a statistically significant improvement of the average HUS among the hearing-impaired Thais in our study. Even though the use of a hearing aid can improve the quality of life of hearing-impaired persons as indicated through various questionnaires ${ }^{22}$, our study failed to confirm it. This implies that the EQ-5D-5L questionnaire might not be useful for analyzing the cost-effectiveness of hearing aid fitting in hearing-impaired Thais because QALYS gained cannot be calculated from no HUS improvement. Other studies have also found that the use of hearing aids did not result in a statistically significant improvement in the HUSs based on the EQ-5D-5L questionnaire, and they concluded this was because it lacks sufficient sensitivity to detect such changes. ${ }^{23-25}$ However, it should also be noted that our study did not show pre- and post-intervention (hearing aid fitting) HUSs. Therefore, our results should be interpreted with caution because we did not have baseline HUSs for our subjects who were using a hearing aid at the time of the study, and the true change of the HUSs after hearing aid fitting cannot clearly be shown. Even though our study could not show a statistically significant difference in the HUSs between subjects using and not using hearing aids, a mean change in HUSs was found in patients who had received a cochlear implantation. For instance, mean statistically significant differences in the HUSs of $0.14^{26}, 0.18^{27}$ and $0.26^{28}$ have been reported between subjects with and without cochlear implantations by using the EQ-5D-5L questionnaire. Therefore, we believe that the EQ-5D-5L questionnaire is still a useful tool, which can be used to assess health-related quality of life and for economic evaluations of hearing-impaired persons, especially those who receives cochlear implants. There were three limitations to our study. Firstly, as our study setting is a tertiary care hospital located in southern Thailand where patients from primary and secondary care hospitals, particularly in the southern region, are referred to, thus there was potential selection bias in terms of enrolling participants in the study. As a result, our sample might not be representative of populations from other geographic regions in Thailand. Secondly, we did not recruit subjects who had already received cochlear implants, thus we could not assess significant changes in the quality of life in those patients even though this has been reported as 
statistically significant in studies from other countries. Finally, only a small number of subjects $(n=25)$ who were already using hearing aids were included in the study, and this particular subgroup might be too small to reliably determine whether or not there was a significant improvement in the HUSs from hearing aid fitting.

Further research is required to assess the HUSs among hearing-impaired Thais who have received cochlear implantations. In addition, other questionnaires, for instance the Health Utilities Index Mark III and preferencebased Short Form 6D, should be used in order to evaluate whether or not there are any differences between the HUSs among these various questionnaires collected from hearing-impaired Thais. Also, studies comparing the HUSs among hearing-impaired Thais before and after receiving a hearing aid are warranted.

\section{Conclusion}

In spite of cultural and socioeconomic variations, our study found that the average HUSs among hearingimpaired Thais were 0.81 to 0.86 , similar to the results from other nations. Additionally, we found the degree of hearing loss had a negative correlation with the HUSs; however, the mean HUS difference in subjects using and not using hearing aids was not statistically significant.

\section{Funding sources}

The study was supported by a grant from the Faculty of Medicine, Prince of Songkla University.

\section{Conflict of interest}

None

\section{References}

1. Karchmer MA, Allen TE. The functional assessment of deaf and hard of hearing students. Am Ann Deaf 1999;144:67-77.

2. World Health Organization. Deafness prevention [homepage on the Internet]. Geneva: WHO; 2018 [cited 2019 Jul 17]. Available from: https://www.who.int/deafness/estimates/en/

3. Prasansuk S. Incidence/prevalence of sensorineural hearing impairment in Thailand and Southeast Asia. Audiology 2000; 39:207-11.

4. World Health Organization. State of hearing \& ear care in the south-east Asia region [homepage on the Internet]. Geneva: WHO; 2009 [cited 2018 Nov 17]. Available from: http://apps. searo.who.int/pds_docs/B1466.pdf

5. Official Statistics Registration System. Thai population 2018 [homepage on the Internet]. Bangkok: Official Statistics Registration System; 2018 [cited 2019 Aug 21]. Available from: http://stat.dopa.go.th/stat/statnew/upstat_age_disp.php

6. Office of the Civil Service Commission. Thai government manpower 2017 [homepage on the Internet]. Bangkok: OCSC; 2018 [cited 2019 Aug 29]. Available from: https://www.ocsc. go.th/gmis/downloads

7. Grosse SD, Prosser LA, Asakawa K, Feeny D. QALY weights for neurosensory impairments in pediatric economic evaluations: case studies and a critique. Expert Rev Pharmacoecon Outcomes Res 2010;10:293-308.

8. Bos JM, Rümke H, Welte R, Postma MJ. Epidemiologic impact and cost-effectiveness of universal infant vaccination with a 7-valent conjugated pneumococcal vaccine in the Netherlands. Clin Ther 2003;25:2614-30.

9. Bos JM, Rümke HC, Welte R, Spanjaard L, van Alphen L, Postma MJ. Combination vaccine against invasive meningococcal B and pneumococcal infections. Pharmacoeconomics 2006;24:141-53.

10. Melegaro A, Edmunds WJ. Cost-effectiveness analysis of pneumococcal conjugate vaccination in England and Wales. Vaccine 2004;22:4203-14.

11. Oostenbrink R, Moll HA, Essink-Bot ML. The EQ-5D and the Health Utilities Index for permanent sequelae after meningitis: a head-to-head comparison. J Clin Epidemiol 2002;55: 791-9.

12. Tongsiri S, Cairns J. Estimating population-based values for EQ-5D health states in Thailand. Value Health 2011;14:1142-5.

13. Thavorncharoensap M. Measurement of utility. J Med Assoc Thai 2014;97:S43-9.

14. Pascolini D, Smith A. Hearing Impairment in 2008: a compilation of available epidemiological studies. Int J Audiol 2009; 48:473-85. 
15. Barton GR, Bankart J, Davis AC, Summerfield QA. Comparing utility scores before and after hearing-aid provision. Appl Health Econ Health Policy 2004;3:103-5.

16. Pattanaphesaj J, Thavorncharoensap M, Ramos-Goñi JM, Tongsiri S, Ingsrisawang L, Teerawattananon Y. The EQ-5D-5L valuation study in Thailand. Expert Rev Pharmacoecon Outcomes Res 2018;18:551-8.

17. Helvik AS, Jacobsen G, Wennberg S, Arnesen H, Ringdahl A, Hallberg LR. Activity limitation and participation restriction in adults seeking hearing aid fitting and rehabilitation. Disabil Rehabil 2006;28:281-8.

18. Solheim J, Kværner KJ, Falkenberg ES. Daily life consequences of hearing loss in the elderly. Disabil Rehabil 2011;33: 2179-85.

19. Carroll AE, Downs SM. Improving decision analyses: parent preferences (utility values) for pediatric health outcomes. J Pediatr 2009;155:21-5.

20. Oostenbrink R, Moll HA, Essink-Bot ML. The EQ-5D and the Health Utilities Index for permanent sequelae after meningitis: a head-to-head comparison. J Clin Epidemiol 2002;55: 791-9.

21. Oostenbrink R, Oostenbrink JB, Moons KG, Derksen-Lubsen G, Essink-Bot ML, Grobbee DE, et al. Cost-utility analysis of patient care in children with meningeal signs. Int $\mathrm{J}$ Technol Assess Health Care 2002;18:485-96.
22. Nordvik $\varnothing$, Heggdal PO, Brännström J, Vassbotn F, Aarstad AK, Aarstad HJ. Generic quality of life in persons with hearing loss: a systematic literature review. BMC Ear Nose Throat Disord 2018;18:1.

23. Barton GR, Bankart J, Davis AC, Summerfield QA. Comparing utility scores before and after hearing-aid provision. Appl Health Econ Health Policy 2004;3:103-5.

24. Joore MA, Brunenberg DE, Chenault MN, Anteunis LJ. Societal effects of hearing aid fitting among the moderately hearing impaired. Int J Audiol 2003;42:152-60.

25. Grutters JP, Joore MA, van der Horst F, Verschuure $H$, Dreschler WA, Anteunis LJ. Choosing between measures: comparison of EQ-5D, HUI2 and $\mathrm{HUI} 3$ in persons with hearing complaints. Qual Life Res 2007;16:1439-49.

26. Sach TH, Barton GR. Interpreting parental proxy reports of (health-related) quality of life for children with unilateral cochlear implants. Int J Pediatr Otorhinolaryngol 2007;71: $435-45$.

27. Kuthubutheen J, Mittmann N, Amoodi H, Qian W, Chen JM. The effect of different utility measures on the cost-effectiveness of bilateral cochlear implantation. Laryngoscope 2015;125: $442-7$.

28. Lee HY, Park EC, Joong Kim H, Choi JY, Kim HN. Costutility analysis of cochlear implants in Korea using different measures of utility. Acta Otolaryngol 2006;126:817-23. 